\title{
Prevalence and Pattern of Alcohol Use among Adults in an Urban Slum in South East Nigeria
}

\author{
Obinna Donatus Onodugo', Birinus Adikaibe Ezeala-Adikaibe1,2*, Obumneme Benneth Anyim², \\ Mark Ezeme'2, Uchenna Nkemdilim Ijoma1, Ijeoma Nnenne Obumneme-Anyim³, \\ Osita Ikenna Okoli ${ }^{1}$, Pauline Nkiruka Onodugo ${ }^{1}$, Paul Chibuike Okoli ${ }^{2}$, Oluchi Stella Ekenze ${ }^{1}$
}

\footnotetext{
${ }^{1}$ Department of Medicine, University of Nigeria Teaching Hospital, Enugu, Nigeria

${ }^{2}$ Department of Medicine, Enugu State University Teaching Hospital, Enugu, Nigeria

${ }^{3}$ Department of Pediatrics, University of Nigeria Teaching Hospital, Enugu, Nigeria

Email: ^birinusadikaibe@gmail.com
}

How to cite this paper: Onodugo, O.D., Ezeala-Adikaibe, B.A., Anyim, O.B., Ezeme, M., Ijoma, U.N., Obumneme-Anyim, I.N., Okoli, O.I., Onodugo, P.N., Okoli, P.C. and Ekenze, O.S. (2019) Prevalence and Pattern of Alcohol Use among Adults in an Urban Slum in South East Nigeria. Open Journal of Psychiatry, 9, 179-191.

https://doi.org/10.4236/ojpsych.2019.92014

Received: March 8, 2019

Accepted: April 22, 2019

Published: April 25, 2019

Copyright $\odot 2019$ by author(s) and Scientific Research Publishing Inc. This work is licensed under the Creative Commons Attribution International License (CC BY 4.0).

http://creativecommons.org/licenses/by/4.0/ (c) (i) Open Access

\begin{abstract}
Background: Alcohol is one of the most commonly abused psychoactive substances in the country. Studies have shown sharp increases in alcohol consumption among Nigerians. This increase is likely to continue because of increased local production and availability of alcohol in the country. Knowledge of the prevalence and pattern of current alcohol use is important considering the public health and socio-economic effects of alcohol use. Methods: Using a semi-structured questionnaire, we estimated the prevalence of current alcohol use among adults 18 years and older living in urban slums in Enugu South East Nigeria. Current use of alcohol was defined as use of any or all alcohol beverages in the past 4 weeks. The safe limit of alcohol was defined using WHO guidelines. Study duration was 5 months. Results: A total of 1411 individuals were recruited into the study. Males were 658 (46.6\%) and females were 753 (53.4\%). The overall prevalence of current use of alcohol was $66.7 \%$; males $75.7 \%$ and females $58.8 \%(\mathrm{p}<0.01)$. The commonest alcoholic beverage consumed was beer $37.1 \%$. The peak age of consumption was $40-49$ years followed by $50-59$ years. About $8.1 \%$ drank alcohol above the generally recommended units per week while $5.2 \%$ drank above the safe limit for chronic liver disease. Significant correlates of alcohol intake were increasing age, male gender, having a job, cigarette smoking and the use of snuff. Significant correlates for excessive consumption of alcohol were increasing age and cigarette smoking while those for exceeding the safe limit chronic liver were increasing age, male gender and cigarette smoking. Conclusion: There is a high prevalence of current alcohol use among urban slums in Enugu. Public health educational measures for reducing alcohol consumption should be encouraged. Efforts should be made to educate the populace on the need for abstinence.
\end{abstract}




\section{Keywords}

Alcohol, Beer, Stout, Enugu, Nigeria, Urban Dwellers

\section{Introduction}

Alcohol consumption is widespread in Nigeria. It is one of the most commonly abused psychoactive substances in the country [1] [2] [3] [4]. The increasing use of alcohol in Nigeria has been attributed to different factors such as socio-cultural practices, rapidly changing lifestyles and increasing purchasing power [5]. Studies from the 90s showed a sharp increase in alcohol consumption among Nigerians [6] which has continued up to the present day. This increase may also be attributed to increased local production of alcohol within the same period of time [7].

The prevalence of current alcohol use varies between regions, age groups, gender and socioeconomic status. Studies from the western part Nigeria revealed a prevalence of current use of alcohol between 14\% - 32.7\% depending on gender and location [8] [9] [10] [11]. More recent studies clearly reveal persisting high rates of alcohol use especially among the young [4] [5] [12] [13]. A study from South-South Nigeria among an Ijaw community reported a $90 \%$ one-prevalence of alcohol use and a 23.7\% [14] prevalence of current use. In South East Nigeria, the current rate of alcohol use has been reported to be the highest in the country [4]. Prevalences as high as $63 \%$ to $78.4 \%$ have been reported among undergraduates [12] [13]. Studies from other West African countries showed a self-reported current use of alcohol 62.2\% [15].

Current alcohol use has been associated with age, gender, marital status, level of education, socioeconomic class, employment status and religious beliefs [5] [8]. While the health benefits of drinking alcohol at low amounts remain controversial [16]; alcohol consumption is related to several acute and chronic diseases, family and social disruptions as well as physical injuries [6] [16] [17]. In one rural study from South-South Nigeria, about $33 \%$ of the subjects had harmful drinking, while $12.73 \%$ had alcohol dependence problem [14]. Documented associated factors for high alcohol consumption include male gender, age, low educational level, lower socioeconomic status and marital status [5] [14] [18].

Types of alcoholic beverages consumed in Nigeria vary between localities. The most commonly consumed alcoholic beverage is beer according to most studies but the overall pattern depends on the community studied and the year of study [5] [8] [12] [19] [20]. Factors that mediate beverage choice may include cost, availability, cultural orientation and advertisement. Knowledge of the prevalence and pattern of current alcohol use is important considering the public health and socio-economic effects of alcohol use. Such information is scarce from South East Nigeria. The aim of this study was to determine the prevalence and pattern of alcohol use among adults in an urban slum in Enugu, Nigeria. 


\section{Methods}

This was a cross-sectional descriptive study. Using a purposive sampling method, we selected 2 isolated urban slum settlements (Agu-Abor and Ugbodogwu) in Enugu, the capital of Enugu State, south east Nigeria. The two settlements have an estimated adult population of 7000 - 9000 individuals (based on church and local records). The total area occupied by both settlements is approximately $2.5-5 \mathrm{~km}^{2}$ and both are located about $1-2.5 \mathrm{~km}$ from the nearest state-owned teaching hospital. The two settlements were selected purposively because of their relatively isolated location. The inhabitants of Agu-Abor were surveyed over a 4week period (August 12-September 9, 2013), while Ugbodogwu inhabitants were surveyed between November 25-December 21, 2013. This study was approved by the ethics committee of the University of Nigeria Teaching Hospital Ituku/Ozalla, P M B 01129 Enugu. No NHREC/05/01/2008B-FWA00002458-1RB00002323.

\section{Study Protocol}

A semi structured questionnaire was used to collect data on selected socio-demographic characteristics, lifestyle behaviors and medical history. Data on alcohol use was collected using a semi-structured questionnaire (See Appendix), specifically designed by the investigators after a review of the relevant literature [1] [2] [3] [4] [5]. The study was preceded by sensitization meetings in the communities. Prior community awareness announcements in churches and by town criers invited participants to sensitization meeting(s) on the selected day(s). All participants who came out for the survey were interviewed by teams of research assistants using the research questionnaire. All consecutive consenting adults 18 years and above were included in the study, whereas the exclusion criteria were refusal to participate and cognitive decline.

The questionnaire sought to elicit data on alcohol use within the last 30 days. Estimated amount of alcohol used in a week and the type of alcoholic beverage preferred were documented. The quantity of alcohol was estimated using different bottle sizes for beer $(600 \mathrm{~mL})$, stout $(600 \mathrm{~mL}$ and $300 \mathrm{~mL})$, palm wine $(200$ $\mathrm{mL}$ cups) and gin (25 and $50 \mathrm{~mL}$ cups).

Cases of hypertension, diabetes, epilepsy and other medical conditions were recorded if such diagnosis was done in a hospital by medically qualified personnel (physician). Current tobacco use was defined as the use of any form of tobacco products in the past 4 weeks. Current use of alcohol was defined as use of any or all alcohol beverages in the past 4 weeks. The safe limit of alcohol was defined based on WHO guidelines of 21 units for men and 14 units for women per week [21]. The safe limit of alcohol for liver cirrhosis was defined based as of 21 units/week in women and 28 units/week in males [17]. Level of education was the individual's highest educational (formal) attainment based on the Nigerian school system.

The minimum sample size was calculated using the Taro Yamane formula [22], $\mathrm{N}=\mathrm{N} / 1+\mathrm{N}(\mathrm{e})^{2}$. Where: $\mathrm{n}=$ required sample size, $\mathrm{e}^{2}=$ error limit and $\mathrm{N}=$ 
estimated adult population in both settlements.

$\mathrm{N}=$ estimated population of the community (9000), $\mathrm{e}=0.05$.

$\mathrm{N}=9000 / 9000 \times 0.0025=9000 / 22.5=400$.

\section{Statistical Methods}

For database management and statistical analyses, we used the SPSS version 23 (IBM Corporation, New York, USA). Data were presented in tables and figures. For continuous variables, mean values and standard deviation were calculated. Rates were expressed as percentages. Categorical values were compared using the Chi Square test. Mean age was compared using the independent t-test. In all, $\mathrm{p}$ value of $<0.05$ was regarded as statistically significant. Conclusions were drawn at $95 \%$ confidence interval.

\section{Results}

1) General Characteristics of the sample population.

A total of 1411 individuals were recruited in the study. Males were 658 (46.6\%) and females were $753(53.4 \%)$. The male to female ratio of those screened was $0.9: 1$. The participants' age ranged from 18 to 90 years, averaging 34.5 (14.4) years. Males were older than females by about 4 years (mean age: 36.8 vs 32.5 years, $\mathrm{p}<0.01)$.

The peak age group of males and females was 20 - 29 years $(36.3 \%$ and $44.1 \%$ respectively) (Table 1 and Figure 1). Most participants were working at the time of the study (54.8\%) and had at least a senior secondary school education (69.2\%) (Table 1).

2) Lifestyle and Medical History.

Current tobacco use $(232(16.4 \%))$ use was more prevalent in males than females (males 179 (27.2\%) versus females 53 (7\%). P < 0.01) (Table 1). A total of $141(10 \%)$ of the subjects had a history of hypertension, $47(3.3 \%)$ had a history of diabetes and $21(1.5 \%)$ reported a past medical history of stroke. Other

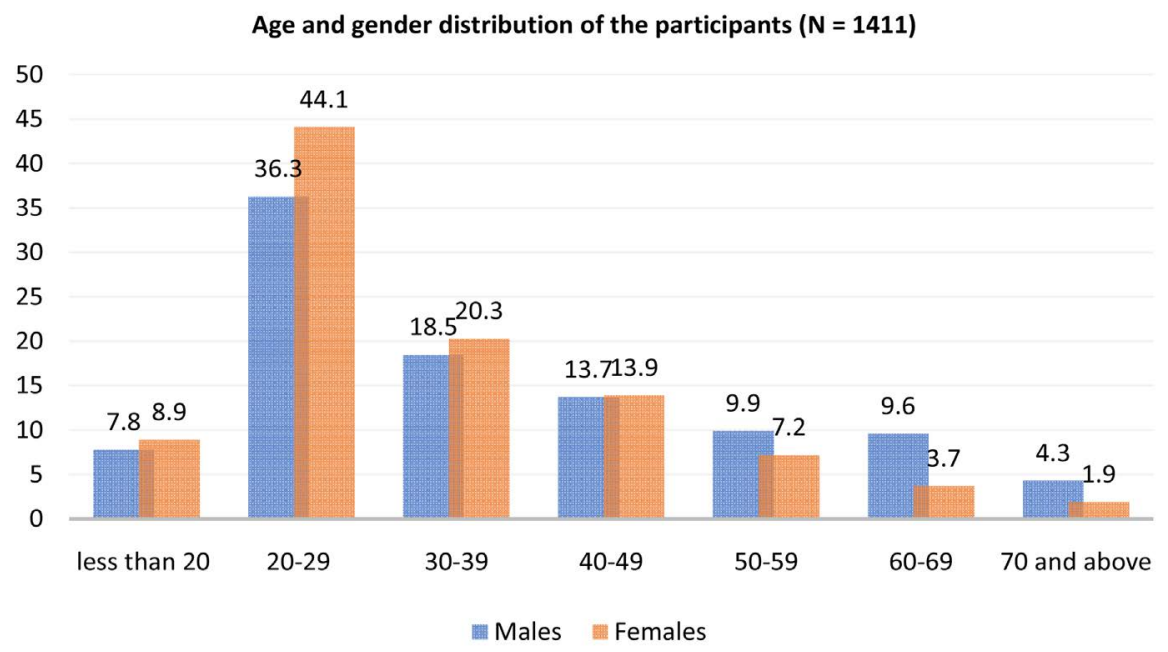

Figure 1. Age and gender distribution of the participants. 
Table 1. Characteristics of participants.

\begin{tabular}{|c|c|c|c|c|}
\hline Characteristic & Female & Male & Total & $P$-value \\
\hline $\mathrm{N}(\%)$ & $753(53.4)$ & $658(46.6)$ & $1411(100)$ & 0.01 \\
\hline Age, years, (sd) & $32.5(12.7)$ & $36.8(15.7)$ & $34.5(14.4)$ & $<0.01$ \\
\hline \multicolumn{5}{|l|}{ Age group years } \\
\hline$<20 \mathrm{n}(\%)$ & $67(8.9)$ & $51(7.8)$ & $118(8.4)$ & \\
\hline $20-29$ n (\%) & $332(44.1)$ & $239(36.3)$ & $571(40.5)$ & \\
\hline $30-39$ n (\%) & $153(20.3)$ & $122(18.5)$ & $275(19.5)$ & \\
\hline $40-49$ n (\%) & $105(13.9)$ & $90(13.7)$ & $195(14.5))$ & \\
\hline $50-59$ n (\%) & $54(7.2)$ & $65(9.9)$ & $119(8.4)$ & \\
\hline $60-69$ n (\%) & $28(3.7)$ & $63(9.6)$ & $91(6.4)$ & \\
\hline$\geq 70$ n (\%) & $14(1.9)$ & $28(4.3)$ & $42(3)$ & $<0.01$ \\
\hline \multicolumn{5}{|l|}{ Occupational status } \\
\hline Students/apprentices & $351(46.6)$ & $240(36.5)$ & $591(41.9)$ & \\
\hline Employed & $381(50.6)$ & $392(59.6)$ & $773(54.8)$ & \\
\hline Retired/unemployed & $21(2.8)$ & $26(4)$ & $47(3.3)$ & \\
\hline \multicolumn{5}{|l|}{ Level of Education } \\
\hline None n (\%) & $2(0.3)$ & $3(0.5)$ & $5(0.4)$ & \\
\hline Primary, n (\%) & $160(21.2)$ & $149(22.6)$ & $309(21.9)$ & \\
\hline Junior Secondary n (\%) & $68(9)$ & $48(7.3)$ & $116(8.2)$ & \\
\hline Senior Secondary n (\%) & $521(69.2)$ & $455(69.1)$ & $976(69.2)$ & \\
\hline Tertiary n (\%) & $2(0.3)$ & $3(0.5)$ & $5(0.4)$ & 0.68 \\
\hline \multicolumn{5}{|l|}{ Lifestyle } \\
\hline Current tobacco use, n (\%) & $53(7)$ & $179(27.2)$ & $232(16.4)$ & $<0.01$ \\
\hline Cigarettes & $10(1.3)$ & $72(10.9)$ & $82(5.8)$ & $<0.01$ \\
\hline Snuff & $44(5.8)$ & $108(16.4)$ & $152(10.8)$ & $<0.01$ \\
\hline Both & $1(0.1)$ & $3(0.5)$ & $4(0.3)$ & $<0.34$ \\
\hline Current Marijuana use, n (\%) & $5(0.7)$ & $18(2.7)$ & $23(1.6)$ & $<0.01$ \\
\hline \multicolumn{5}{|l|}{ Medical History of } \\
\hline Hypertension n (\%) & $79(10.5)$ & $62(9.4)$ & $141(10)$ & \\
\hline Diabetes n (\%) & $21(2.8)$ & $26(4)$ & $47(3.3)$ & \\
\hline Stroke n (\%) & $11(1.5)$ & $10(1.5)$ & $21(1.5)$ & \\
\hline Epilepsy n (\%) & $4(0.5)$ & $3(0.5)$ & $7(0.5)$ & \\
\hline Chronic headache & $94(12.5)$ & $86(13.1)$ & $180(12.8)$ & \\
\hline Chronic cough & $39(5.2)$ & $39(5.9)$ & $78(5.5)$ & \\
\hline Tremor & $1(0.1)$ & - & $1(0.1)$ & \\
\hline Loss of memory & - & $1(0.2)$ & $1(0.1)$ & \\
\hline
\end{tabular}

$P$-values are for the sex differences.

patient-reported medical cases are shown in Table 1.

3) Alcohol consumption.

A total of $941(66.7 \%)$ were currently using alcohol at the time of the study (males $498(75.7 \%)$ versus females $(443(58.8 \%) \mathrm{p}<0.01)$. The commonest alcoholic beverage consumed was beer 524 (37.1\%) which was also used more by males $\mathrm{p}<0.01$. The least consumed alcoholic beverage gin 40 (2.9\%) was equally used by both sexes $(P=0.26)$ (Table 2$)$. Based on the standard alcoholic con- 
tents of alcoholic beverages sold in Nigeria, the mean amount of alcohol (in grams) and the mean unit of alcohol is shown in Table 3. Overall males mean consumption (in grams and units) of alcohol was higher in males than females ( $P$ $\leq 0.01)$. The peak age of consumption was 40 - 49 years followed by 50 - 59 years (Table 4).

Table 5 shows the level of alcohol consumption in the community. A total of $114(8.1 \%)$ drank alcohol above the general recommended units per week while 74 (5.2\%) drank above the safe limit for chronic liver disease. A higher proportion of males $65(9.9 \%)$ than females 49 (6.5\%) drank more than the recommended

Table 2. Alcohol consumption in the community.

\begin{tabular}{ccccc}
\hline Characteristic & Males n (\%) & $\begin{array}{c}\text { Females } \\
\text { N (\%, 95\%, CI) }\end{array}$ & Total & p-value \\
\hline N & $498(75.7)$ & $443(58.8)$ & $941(66.7)$ & $<0.01$ \\
Beer & $327(49.7)$ & $197(26.2)$ & $524(37.1)$ & $<0.01$ \\
Stout & $157(23.9)$ & $201(26.7)$ & $358(25.4)$ & 0.22 \\
Gin & $23(3.5)$ & $17(2.3)$ & $40(2.9)$ & 0.26 \\
Local Brew & $81(12.3)$ & $87(11.6)$ & $168(11.9)$ & 0.66 \\
\hline
\end{tabular}

P-values for sex differences.

Table 3. Mean consumption of different types of alcoholic in the sample population.

\begin{tabular}{ccccc}
\hline Characteristic & $\begin{array}{c}\text { Males, mean } \\
(\mathbf{s d})\end{array}$ & $\begin{array}{c}\text { Females, } \\
\text { Mean }(\mathbf{s d})\end{array}$ & $\begin{array}{c}\text { Total, mean } \\
\text { (sd, range) }\end{array}$ & p-value $^{*}$ \\
\hline Quantity of Alcohol/week(g) & & & & \\
Beer & $55.2(96.5)$ & $23.3(85.6)$ & $38.2(92.2)$ & $<0.01$ \\
Stout & $27.1(8.2)$ & $17.7(49)$ & $22.1(65.1)$ & 0.01 \\
Gin & $1.2(54.5)$ & $0.6(5.7)$ & $0.9(7)$ & 0.12 \\
Local brews & $12.2(54.5)$ & $7.3(36.7)$ & $9.6(45.9)$ & 0.05 \\
Total & $95.6(183.1)$ & $48.9(119.2)$ & $70.7(154.1)$ & $<0.01$ \\
Unit of alcohol & $9.6(18.3)$ & $5.0(11.9)$ & $7.1(15.4)$ & $<0.01$ \\
\hline
\end{tabular}

Table 4. Overall mean consumption of alcohol.

\begin{tabular}{|c|c|c|c|c|}
\hline Characteristic & Mean, gr (sd) & p-value & $\begin{array}{c}\text { Unit of alcohol, } \\
\text { mean (\%) }\end{array}$ & p-value* \\
\hline $\mathrm{N}$ & $70.7(154.1)$ & & $7.1(15.4)$ & \\
\hline Males & $95.6(183.1)$ & & $9.7(18.3)$ & \\
\hline Females & $48.9(119.2)$ & & 4.9 (11.9) & \\
\hline $20-29$ & $21.4(35.6)$ & & $2.1(3.6)$ & \\
\hline $30-39$ & $63.5(121.1)$ & & $6.4(12.1)$ & \\
\hline $40-49$ & $95.3(237.6)$ & & $95(23.4)$ & \\
\hline $50-59$ & $81.6(155.8)$ & & $8.2(15.6)$ & \\
\hline $60-69$ & $78.2(100.3)$ & & $7.8(10)$ & \\
\hline$\geq 70$ & $52.1(84.5)$ & 0.001 & $5.2(8.4)$ & 0.001 \\
\hline
\end{tabular}

${ }^{*} \mathrm{P}$ values for sex differences. 
Table 5. Drinking pattern in the population.

\begin{tabular}{cccccc}
\hline Characteristic & $\begin{array}{c}\text { Not drinking } \\
\mathbf{n}(\%)\end{array}$ & $\begin{array}{c}\text { Drinks } \\
\text { within the } \\
\text { safe limit } \\
\mathbf{n}(\%)\end{array}$ & $\begin{array}{c}\text { Drinks above } \\
\text { the safe limit } \\
\text { n (\%) }\end{array}$ & $\begin{array}{c}\text { Drinks above } \\
\text { the safe limit } \\
\text { for CLD } \\
\mathbf{n}(\%)\end{array}$ & p-value* \\
\hline N & $473(33.5)$ & $824(58.4)$ & $114(8.1)$ & $74(5.2)$ & \\
Females & $312(41.4)$ & $392(52.1)$ & $49(6.5)$ & $48(7.3)$ & \\
Males & $161(24.5)$ & $432(65.7)$ & $65(9.9)$ & $26(3.5)$ & $<0.01^{*}$ \\
Age group & & & & & \\
$<20$ & $68(57.6)$ & $50(6.1)$ & - & - & \\
$20-29$ & $197(41.6)$ & $335(40.7)$ & $39(6.8)$ & $24(4.2)$ & \\
$30-39$ & $83(17.5)$ & $161(19.5)$ & $31(11.3)$ & $21(7.6)$ & \\
$40-49$ & $50(10.6)$ & $125(15.2)$ & $20(10.3)$ & $14(7.2)$ & \\
$50-59$ & $39(8.2)$ & $68(8.3)$ & $12(10.1)$ & $7(9.5)$ & \\
$60-69$ & $19(20.9)$ & $62(7.5)$ & $10(11)$ & $6(8.1)$ & \\
$\geq 70$ & $17(3.6)$ & $23(2.8)$ & $2(4.8)$ & $2(2.7)$ & \\
\hline
\end{tabular}

${ }^{\star} \mathrm{P}$ value for sex differences; ${ }^{\mathrm{p}} \mathrm{p}$ value similar for population recommended levels and for chronic liver disease.

weekly limit. The age distribution of units consumed per week showed that from 30 to 69 years the proportion of those drinking more than recommended unit was similar. While all those less than 20 years drank safely, $4.8 \%$ of individuals 70 years and above exceeded the recommended levels. With reference to the recommended safe limit of alcohol for chronic liver disease: 74 (5.2\%) of the population surveyed exceeded that limit (males 48 (7.3\%) and females $26(3.5 \%)$ $\mathrm{p}<0.01)$. The age distribution of excess consumption of alcohol peaked at $50-$ 69 years.

Significant correlates alcohol consumption were increasing age, male gender (females 0 , males 1), occupational status (unemployed 0 , employed 1), cigarette smoking (no 0 , yes 1 ) and the use of snuff (no 0 , yes 1 ). Significant correlates for excessive consumption of alcohol were increasing age and cigarette smoking (no 0 , yes 1 ) while that for exceeding the safe limit chronic liver were increasing age, male gender (females 0 , males 1 ) and cigarette smoking (no 0, yes 1 ) (Table 6).

\section{Discussion}

Alcohol consumption in Nigeria is embedded into cultural and religious practices especially in the Christian dominated South East of the country. It is the most commonly abused psychoactive substance in the country [1] [2] [4] [9] [10]. With changing lifestyles, increasing purchasing power and availability of alcoholic beverages, the use of alcohol will definitely continue to increase in the country.

In the index study the prevalence of current alcohol use was $66.7 \%$, greater in males $498(75.7 \%)$ than females $443(58.8 \%)$. The preferred alcoholic beverage was beer $524(37.1 \%)$ while the least was gin 40 (2.9\%) with a peak age of $40-49$ 
Table 6. Correlates of level of alcohol consumption.

\begin{tabular}{cccc}
\hline Variable & $\begin{array}{c}\text { Alcohol use } \\
\mathrm{r}(\mathrm{p} \text {-value })\end{array}$ & $\begin{array}{c}\text { Safe Limit } \\
\mathrm{r} \text { (p-value })\end{array}$ & Safe Limit CLD \\
\hline Age & $0.14(<0.01)$ & $0.09(0.01)$ & $0.08(0.02)$ \\
Gender & $0.18(<0.01)$ & $0.03(0.34)$ & $0.07(0.03)$ \\
Level education & $0.00(0.85)$ & $0.04(0.23)$ & $0.03(0.33)$ \\
${ }^{*}$ ES & $0.13(<0.01)$ & $0.14(<0.01)$ & $0.14(<0.01)$ \\
Cigarette & $0.16(<0.01)$ & $0.12(0.01)$ & $0.12(0.01)$ \\
Snuff & $0.20(<0.01)$ & $0.02(0.47)$ & $0.04(0.21)$ \\
\hline
\end{tabular}

${ }^{*}$ CLD Chronic liver disease. ${ }^{*}$ ES employment status. Students, apprentices and retired individuals were counted as unemployed.

years followed by 50 - 59 years. A total of 114 (8.1\%) individuals drank alcohol more than the recommended units per week (males 65 (9.9\%) more than females $49(6.5 \%)$ with a peak age of $20-29$ years. With reference to the recommended safe limit of alcohol for chronic liver disease; 7 (5.2\%) of the population surveyed exceeded that limit with a peak age at 50 - 69 years. Significant correlates of alcohol consumption were increasing age, male gender, being employed, cigarette smoking and the use of snuff. Among these variables, age, being employed and cigarette smoking correlated with exceeding the general safe limit of alcohol consumption, while age, gender, being employed and cigarette smoking were significant correlates of exceeding the set limit for liver disease.

The $5.8 \%$ rate of current cigarette smoking and $10.8 \%$ rate of snuff use is within the previously reported ranges in the country [4] [23]. Together with alcohol tobacco is one of the most commonly abused psychoactive drugs in Nigeria [1] [2] [4] [9] [10] [23] [24]. The prevalence of current cigarette and snuff use in population based studies range between $5.3 \%$ to $17.6 \%$ and $4.1 \%$ to $9.6 \%$ respectively [4] [24]. Similar to some of these studies, tobacco was used commonly among males. The high rate of snuff use in this study may be related to cultural and religious norms. In dominant Igbo culture of south east Nigeria, snuff use is more culturally acceptable in both males and females.

About $10 \%$ of the subjects had a history of hypertension, $3.3 \%$ had a history of diabetes and $1.5 \%$ reported a past medical history of stroke. The relationship between these disorders and alcohol use is well documented [25]. Alcohol consumption is likely to increase both morbidity and mortality of these disorders. Other patient reported medical cases in the index study may or may not be related to alcohol nevertheless alcohol is a risk factor for some of these disorders [16] [17].

The prevalence of current consumption of alcohol was 66.7\%: more in males $75.7 \%$ than in females $58.8 \%$. In the past 30 years the rate of alcohol consumption has increased across all regions of Nigeria [3]. Data from a recent nation-wide study supported this trend in all regions of country [4]. The age distribution of alcohol consumption in the index study is different from some and 
similar to other studies [5] [12] [14]. In a study among rural dwellers in South-s Nigeria the reported peak age prevalence of 25 - 44 years was slightly younger than in the index study [5]. The peak age of alcohol consumption may reflect the purchasing power in this group which is also related to their employment status.

The preponderance of male alcohol users seems to be universal [2] [4] [5] [10] [11] [26] [27]. Male consumption of alcohol has been linked to masculinity and high sexual performance [12] [28] [29]. High levels of female consumption have also been documented especially in universities [8] [12] [14]. A higher proportion of males 65 (9.9\%) than females 49 (6.5\%) drank more than the recommended weekly limit of 21 units for males and 14 units for females. Alcohol abuse disrupts social, occupational, interpersonal and marital life and has been related to domestic violence [6] [15] [27]. In one study from North Central Nigeria, $54 \%$ of males and $46 \%$ of female alcohol users were identified as alcohol abusers through the use of a 4-item CAGE instrument [26]. In a study from South Western Nigeria, $69.1 \%$ of current alcohol users were at either moderate or high health risk from alcohol [5]. Other studies have shown that more than $50 \%$ of non-heavy drinkers and of heavy drinkers have felt the effects of alcohol while at work, while driving or have been involved in a road traffic accident [30]. Harmful drinking have been reported in about 33\% of the subjects, while $12.73 \%$ had alcohol dependence problem [14]. The net effect of alcohol consumption on the index population is enormous considering the percentage and age distribution of the population studied. This is even more obvious considering the rate of tobacco use in the population.

Alcohol use was largely accounted by beer and stout. The least consumed alcoholic beverage was gin. This pattern of beverage use is similar to many studies [3] [5] [31] and different from others [14] [19]. The emergence of stout as a common alcoholic beverage may suggest increasing Western cultural influence, higher purchasing power and/or increasing availability. Traditional (brew palm wine) was consumed by $11.9 \%$ of the population. Traditional alcoholic beverages are popular in both rural and urban communities where it is mostly enjoyed with local delicacies. Palm wine is popular in southern eastern Nigerians and contains varying amounts of alcohol 3\% - 6\% [3] [6].

Significant correlates of alcohol consumption in the index study were increasing age, male gender, having a job, cigarette smoking and using snuff. Increasing age, cigarette smoking positively correlated with drinking more than the recommended limit and the recommended limit for CLD. People drinking alcohol above the recommended limit may be regarded as abusers. Unlike the index study, studies from other parts of Nigeria have associated alcohol to younger age [5] [9] [19] [26]. Other documented correlates of current alcohol use and alcohol abuse include being unmarried, low educational level and being unemployed [5] [9] [19] [26]. The higher rate of alcohol consumption in this study may be linked to the dominant christian beliefs [5] [10] [32] (all the people included in the index study were Christians). 
The index study has some limitations. First, the quantity of alcohol used was self-reported and may not be accurate. However, data was collected individually after proper explanation of privacy concerns. Secondly, alcohol drinks in Nigeria have slight variations in their alcohol content. Thirdly, local brews (gin and palm wine) may not have fixed alcoholic content. Despite these limitations this study will provide baseline data for further studies in the region and educational material for public health workers and policy makers.

\section{Conclusion}

There was a high prevalence of alcohol use in the study population. There is a need for public health enlightenment on the dangers of excessive alcohol use. Being employed, increasing age and cigarette smoking correlated positively with exceeding the general safe limit of alcohol consumption.

\section{Conflicts of Interest}

The authors declare no conflicts of interest regarding the publication of this paper.

\section{References}

[1] Okpataku, C.I., Kwanashie, H.O., Ejiofor, J.I. and Olisah, V.O. (2014) Prevalence and Socio-Demographic Risk Factors Associated with Psychoactive Substance Use in Psychiatric Out-Patients of a Tertiary Hospital in Nigeria. Nigerian Medical Journal, 55, 460-464. https://doi.org/10.4103/0300-1652.144695

[2] Adelekan, M.L., Abiodun, O.A., Obayan, A.O., Oni, G. and Ogunremi, O.O. (1992) Prevalence and Pattern of Substance Use among Undergraduates in a Nigerian University. Drug and Alcohol Dependence, 29, 255-261. https://doi.org/10.1016/0376-8716(92)90100-Q

[3] Dumbili, E. (2013) Changing Patterns of Alcohol Consumption in Nigeria: An Exploration of Responsible Factors and Consequences. Medical Sociology Online, 20, 20-33.

[4] Adamson, T.A., Ogunlesi, A.O., Morakinyo, O., Akinwande, A.O., Onifade, P.O., Erinosho, O., Adewuyi, A.A., Fasiku, D.A., Adebowale, T.O., Ogunwale, A., Somoye, E.B. and Olaniyan, O. (2015) Descriptive National Survey of Substance Use in Nigeria. Journal of Addiction and Research Therapy, 6, 3. https://doi.org/10.4172/2155-6105.1000234

[5] Lasebikan, V.O. and Ola, A.B. (2016) Prevalence and Correlates of Alcohol Use among a Sample of Nigerian Semirural Community Dwellers in Nigeria. Journal of Addiction, 2016, Article ID: 2831594. https://doi.org/10.1155/2016/2831594

[6] World Health Organization (2004) Global Status Report on Alcohol 2004. African Region: Country Profiles Nigeria.

[7] WHO (2012) Substance Abuse in Nigeria. http://www.who.int/substance_abuse/publications/en/nigeria.pdf

[8] Mamman, L.S., Brieger, W.R. and Oshiname, F.O. (2002) Alcohol Consumption Pattern among Women in a Rural Yoruba Community in Nigeria. Substance Use and Misuse, 37, 579-597. https://doi.org/10.1081/JA-120004274

[9] Fatoye, F.O. and Morakinyo, O. (2002) Substance Use amongst Secondary School 
Students in Rural and Urban Communities in South Western Nigeria. East African Medical Journal, 79, 299-305. https://doi.org/10.4314/eamj.v79i6.8849

[10] Gureje, O., Degenhardt, L., Olley, B., Uwakwe, R., Udofia, O., Wakil, A., Adeyemi, O., Bohnert, K.M. and Anthony, J.C. (2007) A Descriptive Epidemiology of Substance Use and Substance Use Disorders in Nigeria during the Early 21st Century. Drug and Alcohol Dependence, 91, 1-9. https://doi.org/10.1016/j.drugalcdep.2007.04.010

[11] Adelekan, M.L., Ndom, R.J.E., Makanjuola, A.B., Parakoyi, D.B., Osagbemi, G.K., Fagbemi, O. and Petu, A.O. (2000) Trend Analysis of Substance Use among Undergraduates of University of Ilorin, Nigeria, 1988-1998. African Journal of Drug and Alcohol Studies, 1, 39-52.

[12] Chikere, E.I.C. and Mayowa, M.O. (2011) Prevalence and Perceived Health Effect of Alcohol Use among Male Undergraduate Students in Owerri, South-East Nigeria: A Descriptive Cross-Sectional Study. BMC Public Health, 11, 118.

https://doi.org/10.1186/1471-2458-11-118

[13] Chineke, H.H., Diwe, K.C., Emerole, C.O. and Ezemenah, B.E. (2014) The Prevalence of Alcohol Consumption among Undergraduates of Imo State University Owerri, Nigeria. Orient Journal of Medicine, 26, 1-2.

[14] Brisibe, S. and Ordinioha, B. (2011) Socio-Demographic Characteristics of Alcohol Abusers in a Rural IJAW Community in Bayelsa State, South-South Nigeria. Annals of African Medicine, 10, 97-102. https://doi.org/10.4103/1596-3519.82066

[15] Agoudavi, K., Dalmay, F., Legleyle, S., Kumako, K., Preux, P.M., Clement, J.P., Falissard, B. and Nubukpo, P. (2015) Epidemiology of Alcohol Use in the General Population of Togo. Addictive Behaviors Reports, 2, 1-5. https://doi.org/10.1016/j.abrep.2015.03.004

[16] Rehm, J., Mathers, C., Popova, S., Thavorncharoensa, M., Teerawattananon, Y. and Patra, J. (2009) Alcohol and Global Health 1. Global Burden of Disease and Injury and Economic Cost Attributable to Alcohol Use and Alcohol-Use Disorders. The Lancet, 373, 2223-2233. https://doi.org/10.1016/S0140-6736(09)60746-7

[17] Collier, J.D. and Webster, G. (2010) Liver and Biliary Tract Disease. In: Colledge, N.R., Walker, B.R. and Ralston, S.H., Eds., Davidson's Principle and Practice of Medicine, $21^{\text {st }}$ Edition, Churchill Livingstone Elsevier, London, 954-958. https://doi.org/10.1016/B978-0-7020-3085-7.00023-7

[18] World Health Organization (2010) The ASSIST-Linked Brief Intervention for Hazardous and Harmful Substance Use Manual for Use in Primary Care. World Health Organization, Geneva.

[19] Gureje, O. and Lasebikan, V.O. (2006) Alcohol Beverage Type, Problem Drinking and Self-Reported Health Status. Nigerian Journal of Psychiatry, 4, 4-8.

[20] Bennett, L.A., Campillo, C., Chandrashekar, C.R. and Gureje, O. (1998) Alcoholic Beverage Consumption in India, Mexico, and Nigeria: A Cross-Cultural Comparison. Alcohol Health and Research World, 22, 243-252.

[21] World Health Organization (2018) Global Status Report on Alcohol and Health 2018.

[22] Yamane, T. (1967) Statistics: An Introductory Analysis. 2nd Edition, Harper and Row, New York.

[23] Umukoro, O.L., Taiwo, A., Maroh, I. and Mofoluwake, M. (2016) Prevalence and Pattern of Drug Abuse among Students of Tertiary Institution Students in Abeokuta, Ogun State, Nigeria. International Journal of Psychiatry, 1, 3-6.

[24] Adeyemo, F.O., Ohaeri, B., Okpala, P.U. and Oghale, O. (2016) Prevalence of Drug 
Abuse amongst University Students in Benin City, Nigeria. Public Health Research, 6, 31-37.

[25] BeLue, R., Okoror, T.A., Iwelunmor, J., Taylor, K.D., Degboe, A.N., Agyemang, C. and Ogedegbe, G. (2009) An Overview of Cardiovascular Risk Factor Burden in Sub-Saharan African Countries: A Socio-Cultural Perspective. Globalization and Health, 5, 10. https://doi.org/10.1186/1744-8603-5-10

[26] Grittner, U., Kuntsche, S., Graham, K. and Bloomfield, K. (2012) Social Inequalities and Gender Differences in the Experience of Alcohol-Related Problems. Alcohol and Alcoholism, 47, 597-605. https://doi.org/10.1093/alcalc/ags040

[27] Stanley, P.C. and Dejide, A.O. (2002) Social Demographic and Forensic Characteristics of Alcohol Abusers in Jos Nigeria. Nigerian Journal Medicine, 3, 113-117.

[28] Ibanga, A.J., Adetola, A.V., Dagona, Z., Karick, A. and Ojiji, O. (2005) The Contexts of Alcohol Consumption in Nigeria. In: Obot, I.S. and Room, R., Eds., Alcohol, Gender and Drinking Problem: Perspectives from Low and Middle Income Countries, WHO, Department of Mental Health and Substance Abuse, Geneva, 143-166.

[29] Suggs, D.N. (2001) These Young Chaps Think They Are Just Men, Too: Redistributing Masculinity in Kgatleng Bars. Social Science Medicine, 53, 241-250. https://doi.org/10.1016/S0277-9536(00)00334-8

[30] Demmel, R. and Hagen, J. (2004) The Structure of Positive Alcohol Expectancies in Alcohol Dependent Inpatients. Addiction Research and Theory, 12, 125-140. https://doi.org/10.1080/1606635310001634519

[31] Obot, I.S. (2001) Household Survey of Alcohol Use in Nigeria: The Middle Belt Study. In: Demers, A., Room, R. and Bourgault, C., Eds., Surveys of Drinking Patterns and Problems in Seven Developing Countries, World Health Organization, Geneva, 63-70.

[32] Chukwuonye, I.I., Chuku, A., Onyeonoro, U.U., Madukwe, O.O., Oviasu, E. and Ogah, O.S. (2013) A Rural and Urban Cross-Sectional Study on Alcohol Consumption among Adult Nigerians in Abia State. International Journal of Medicine and Biomedical Research, 2, 179-185. 


\section{Appendix}

\section{Questionnaire}

This work is designed to find out how many people in Aguabor and Ugbodogwu use alcohol and tobacco and how much of these substances they use. Your identity will not be disclosed to anyone or released for any other purpose except for the goal of this study without your permission.

Initials............. Age............. Sex............. Occupation.........

Level of Education. Primary, Secondary, Tertiary

1) Past medical history

Have you been told that you have or had

Hypertension---Diabetes---Stroke---Epilepsy---Asthma---Sickle Cell disease-others---

2) Use of tobacco and other substances. type...smoking...snuff. Use of Marijuana

Others (describe) cocaine (etc) ASK!

Current......(las 4 weeks) .....glue Past. . .

3) Use of alcohol...current (in the past 4 weeks)

Which type of alcohol do you prefer most of the time:

Beer. Stout Local gin. Palm wine. Wine.

Others.

Give an estimate how much alcohol you took in the last 4 weeks.

Bottles.

Small stout.

Big stout

Drinking glass $(200 \mathrm{mls})$

Shots.

Thank you for cooperating with us. 